\title{
Correction: Information: a missing component in understanding and mitigating social epidemics
}

\author{
Roger D. Magarey (ID \& Christina M. Trexler (I)
}

Correction to: Humanities and Social Sciences Communications https://doi.org/10.1057/s41599-020-00620-w, published online 20 October 2020.

A change has been made to the published paper to correct a misattributed quotation.

The original read: Vectors for infopathogens include media, social media, and advertisers (Norris and Suomela, 2017), but they are not always necessary as infopathogens can spread directly from person to person, especially when people share the same belief systems.

The revised text now reads: Vectors for infopathogens include media, social media, and advertisers, but they are not always necessary as infopathogens can spread directly from person to person, especially when people share the same belief systems.

This has now been corrected online and in the PDF version of the paper.

Published online: 04 January 2021

Open Access This article is licensed under a Creative Commons Attribution 4.0 International License, which permits use, sharing, adaptation, distribution and reproduction in any medium or format, as long as you give appropriate credit to the original author(s) and the source, provide a link to the Creative Commons license,
and indicate if changes were made. The images or other third party material in this article are included in the article's Creative Commons license, unless indicated otherwise in a credit

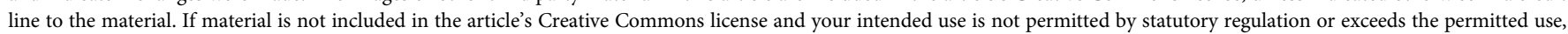
you will need to obtain permission directly from the copyright holder. To view a copy of this license, visit http://creativecommons.org/licenses/by/4.0/.

(C) The Author(s) 2021 